\title{
Francisco de Vasconcelos Coutinho: a (re)descoberta de um poeta madeirense
}

\author{
Francisco de Vasconcelos Coutinho: The (re)discovery of a poet from Madeira
}

\author{
CIDÁLIA Dinis \\ Faculdade de Letras da Universidade do Porto - Porto - Portugal
}

-

\begin{abstract}
Resumo: Natural da cidade do Funchal, Vasconcelos é considerado por muitos especialistas como um dos poetas mais representativos do período barroco português, embora não tenha publicado em vida nenhum dos muitos textos que lhe andavam atribuídos. Escrevendo ora em português, ora em castelhano, as suas composições deixam antever a consciência da efemeridade da vida e o desengano, marcados pela indissociável lembrança da morte, assumindo-se a palavra rebuscada, a metáfora, a antítese como peças fundamentais de puzzles construídos com paciente labor.
\end{abstract}

Palavras-chave: Poesia; Barroco; Morte

\begin{abstract}
Vasconcelos was born in Funchal and he is considered by many specialists as one of the most representative poets of the baroque Portuguese period, although he had not published while alive none of the many texts that have been assigned to him. Writing in Portuguese or in Castilian his compositions make you realize the frailty of life and disappointment marked by the memory of death taking upon the elaborate word, the metaphor, the antithesis as pieces of a puzzle sketched by a patient labour.
\end{abstract}

Keywords: Poetry; Baroque; Death

Considerado por muitos especialistas como um dos poetas mais representativos do período barroco português, Francisco de Vasconcelos Coutinho nasceu (1665) e faleceu (1723) no Funchal - Ilha da Madeira.

Segundo Cabral do Nascimento, que no "Arquivo Histórico da Madeira" (1931, p.52-62) lhe traça uma sumária biografia - a que nós efectuámos alguns acrescentos resultantes das pesquisas que temos vindo a desenvolver, no âmbito do projecto de Doutoramento, no Arquivo da Universidade de Coimbra -, o poeta foi baptizado na igreja de S. Pedro do Funchal a 17 de Maio de $1665^{1}$. Era filho de Lourenço de Matos Coutinho e

\footnotetext{
Cf. Registo do Livro 5을 dos Baptizados de S. Pedro, Funchal, fl. 120.

2 As armas usadas pelos deste apelido são: em campo vermelho, um pinheiro verde com raízes de prata, sustido por dois leões de ouro brilhantes, armados e lampassados de azul, afrontados; timbre: meio leão de ouro armado e lampassado de azul, tendo um ramo de pinheiro nas garras. Manuel de Sousa da Silva deixou, em louvor desta família, os seguintes versos (ZUQUETE, Afonso Eduardo Martins (dir.) - ARMORIAL LUSITANO - Genealogia e Heráldica, Lisboa, Editorial Enciclopédia, 1961, p. 351): O lugar de Matos tem / de Aregos no julgado / o solar assinalado / de Matos, e dele vem / todo o seu grémio honrado.

3 Foi parceiro com seu irmão Bento de Matos Coutinho de uma vasta rede de operações comerciais - que se estendia da Europa até ao Brasil -, presidida pelo judeu Simão Lopes Maciel, estabelecido em Ruão (SALVADOR, José Gonçalves - Os Cristãos-Novos e o Comércio no
}

de Mariana de Vasconcelos, fundadores no ano de 1670 da Capela de Nossa Senhora da Quietação, no sítio dos Alecrins, no Funchal.

É na figura de Luís Fernandes de Matos (bisavô do poeta $)^{2}$, descendente dos reis de Oviedo e Leão, que passou à Madeira, cerca de 1580, que reside a origem mais remota desta família. Luís de Matos era filho do cavaleiro António Vaz de Matos, que acompanhou Afonso de Albuquerque à Índia, e de Francisca de Brito Coutinho; foi comerciante e casou com Guiomar Antunes, com quem teve dois filhos: Lourenço de Matos Coutinho ${ }^{3}$ e Bento de Matos Coutinho (avô do poeta), estudante de Cânones

\footnotetext{
Atlântico Meridional, S. Paulo, Livraria Pioneira Editora, 1978, p. 254). As relações comerciais que mantinha conjuntamente com o seu irmão são aludidas na sua disposição testamentária, redigida em Fevereiro de 1654 Nela, declarava o cristão-novo que lhe tinham ficado a dever "muitas dividas no Brazil e pera se cobrarem mandamos eu e o dito lesenseado Bento de Matos Coutinho meo irmão procurassão a seo filho natural Luis de Matos Coutinho que asiste nas ditas partes do Brazil e que cobradas ellas houvesse a metade pêra si" (ARM, Tombo do Juizo dos Resíduos e Capelas, Cx. 7, Maço 9).

Faleceu em 26 de Novembro de 1654 (ARM, RP, Óbitos da Sé, Livro 8 no 74, fl. 1v). Residiu, durante algum tempo, no outro lado do Atlântico. Constitui prova a sua cédula testamentária, em que o cristão-novo deixou forra uma sua escrava, declarando que ele próprio a trouxera do Brasil (ARM, Tombo do Juizo dos Resíduos e Capelas, Cx. 7, Maço 9).
} 
com o primeiro registo de matrícula a 1 de Outubro de $1607^{4}$, bacharel em Cânones a 21 de Maio de $1613^{5}$ e com Formatura a 6 de Março de $1614^{6}$ pela Universidade de Coimbra. Foi mercador, auditor e "juiz dos castelhanos" .

A 7 de Outubro de $1625^{8}$, Bento de Matos Coutinho casa com D. Filipa de Vasconcelos ${ }^{9}$. Deste casamento, nasceram António Teixeira de Vasconcelos ${ }^{10}$, filho segundo, e Lourenço de Matos Coutinho (homónimo de seu tio paterno), chamado "o Cavaleiro", pai do poeta.

Vítima de um delator anónimo, Bento de Matos Coutinho é denunciado à Inquisição, não só pelo facto de ter parentes detidos nos cárceres do Santo Ofício e de ser um intermediário privilegiado nos "tratos e negoçios com judeus que estam fugidos em Flandes e com outros que vivem em França e no Brazil e na cidade de Lisboa", como também por se insurgir publicamente contra as acções repressoras dos inquisidores, considerando-as injustas, "e que procedião com excessos contra a gente de nação", causando as suas palavras "muito escandalo" aos ouvintes. Além disso, é ainda acusado de se congratular com a morte do inquisidor Simão Barreto - supostamente envenenado pelos judeus, durante uma "jornada" no Reino -, afirmando, sem pejo algum, "que tambem os inquisidores procedião contra elles tiranicamente contra direito e justiça"l1.

O seu envolvimento dissimulado no tráfico fraudulento de mercadorias parece ter sido aliás uma realidade. Faria descarregar e embarcaria furtivamente toda a sorte de fazendas, ao abrigo da escuridão da noite, junto à Fortaleza de São Lourenço, e, para as suas actividades ilícitas, teria até edificado uma casa numa zona escusa da Praia Formosa. Era detentor do seu próprio navio, circunstância que lhe proporcionava, decerto, ampla margem de acção. No Arquivo da Família Ornelas Vasconcelos, encontrámos um documento que tece considerações pouco abonatórias sobre as actividades fraudulentas atribuídas a Bento de Matos Coutinho. Tratase de uma cópia, de 1828, dum "antigo" manuscrito que se achava, nesse ano, em poder do escrivão da Câmara do Funchal. No caso em apreço, vale a pena transcrevê-la parcialmente:

Este Licenciado Bento de Mattos Coitinho ou Coitadinho teve inteligencia para se enthoronizar por Auditor e Juis Accessor do Prezidio dos Lagartões Castelhanos e tão arrogante e soberbo que largava palavras muito descompostas contra os Governadores para adquirir mais jurisdicção à Coroa de Castella e chegou a tanto que intitolou os Capitães do Prezidio Castelhano Governadores da gente de guerra pella Coroa de Castella; tudo errado e impróprio por quanto a gente que assistia na Fortaleza dos Lagartões, erão pagos pela Fazenda Real e Coroa de Portugal, em que consumião os Officiaes maiores as duas partes do que se despendia, que erão mais de seis contos em cada hum anno, e de tudo rezultava grande prejuízo a Fazenda Rel e damnos ao Clero e Igrejas desta Ilha; e tornando ao ditto Licenciado Bento de Mattos Coutinho, elle se fés tão poderozo e famoso com o titulo de Auditor e Accessor dos Lagartões Castelhanos, que dezembarcava cada ves que vinhão navios de França, Flandes e Inglaterra todas as fazendas de noite à sombra do Prezidio junto das Fontes pela parte que vai dellas à Cruz de Sam Francisco e pela mesma passagem embarcava quantas fazendas queria $[\ldots]$ navios $[\ldots]$ as ditas partes e Indias de Castella e para o Brazil e tantos [...]os direitos à Fazenda Real, e tanto hé notorio este modo de furtar os direitos reaes que comprou huma fazenda em que fez cazas terras na Praia Formoza junto ao mar que he huma enseada, legoa desta cidade, e parte escuza, aonde despois por vezes dezembarcava muitas fazendas dos navios estrangeiros e as mandava vir por terra em cavalgaduras de noite para sua caza ${ }^{12}$.

4 Cf. Livro de Matrículas 1600-1612, vol. III, fl. 8 do Arquivo da Universidade de Coimbra (AUC) (vide fig. 1).

5 Cf. Actos e Graus 1610-1613, vol. XXIII, fl. 35 do AUC.

6 Cf. Actos e Graus 1613-1616, vol. XXIV, fl. 50v do AUC (vide fig. 2).

Em Fevereiro de 1623, a "gente da guerra" do presídio - que não recebia os respectivos salários há já sete meses, devido à alegada falta de rendimentos da Alfândega do Funchal - achava-se, como inúmeras vezes sucedeu, "no mais mizeravel estado que ser podia por cauza da fome que padesia". O capitão D. António de Herédia deslocou-se no dia 9 desse mês à Câmara do Funchal, a fim de solicitar "algum socorro com toda a presteza posivel". Para o efeito, fez-se acompanhar dos seguintes membros do presídio: Luís Fernandes de Oliveira, contador, Simão Rodrigues Vila Real, escrivão, Pêro de Barreda, sargentomor, o licenciado Bento de Matos Coutinho, "juiz dos castelhanos", o licenciado Luís Dias Guterres, médico, o licenciado Manuel Dias, cirurgião, e o padre capelão Bento de Oucim (ARM, CF, Vereações de 1623, no 1323, ff. 16-18). Vide, igualmente, a Carta do Marquês de Alenquer confirmando o cargo de auditor do presídio ao licenciado Bento de Matos Coutinho, de 17 de Agosto de 1617 (ARM, CF, RG, T. 3 , no 1214 , ff. 120v-121).

8 Cf. Registo Paroquial da Madeira - Registo de Casamento, Faial, livro 722, fl. $59 \mathrm{v}$

9 João Rodrigues de Sá, senhor de Matosinhos, que viveu no século XVI, dedicou as seguintes quintilhas aos Vasconcelos (ZUQUETE, Afonso Eduardo Martins (dir.) - ARMORIAL LUSITANO, cit., p. 541-543): As que mil temores fazem/ a quem há-de navegar/vermelhas ondas do mar/ os de Vasconcelos trazem/sobre azul mui singular./Vasconcelos de Gasconha/ que nunca passou vergonha/ em esforço e valentia,/ no tempo que florecia/ nem agora há quem lhe ponha.

Também Manuel de Sousa da Silva, capitão-mor de Santa Cruz da Riba-Tâmega, genealogista do século XVII, escreveu acerca da mesma linhagem: Junto ao Cavado se vê/ em Ferreiros assentado/ o solar nobre e honrado/dos Vasconcelos em pél as paredes sem telhados.

${ }^{10}$ Segundo alguns genealogistas, António Teixeira de Vasconcelos terá vivido na quinta do Vale de Amores, na freguesia da Calheta, na qual se encontrava erguida uma capela da invocação de S. António.

Em 1654, o seu tio paterno Lourenço de Matos Coutinho instituiu, na sua cédula testamentária, um encargo perpétuo destinado ao "azeite da alampada da capella de Santo Antonio que esta na quinta de Val Damores na Calheta". O antigo sítio chamado Vale de Amores - topónimo que remonta ao século XV -, onde se levanta a vetusta ermida de Santo António, acha-se hoje no Lombo do Salão (ARM, Tombo do Juizo dos Resíduos e Capelas, Cx. 7, Maço 9). Ficámos ainda a saber que a 26 de Maio de 1660 se casa com D. Paula de Ornelas, sendo "despensados no $2^{\circ}$ grão de consanguinidade" (ARM, FOV, Cx. 40, n⿳o 68, fl. 52).

${ }^{11}$ Cf. ANTT, Inquisição de Lisboa, Cadernos do Promotor, no 21, Livro, 222 , ff. $47-47 \mathrm{v}$

${ }^{12} \mathrm{O}$ copista adverte de que "os pontinhos marcão os lugares que não pude ler" (ARM, FOV, cx. 40, no 67). 
No Brasil, vivia, aliás, um correspondente privilegiado - o seu filho bastardo Luís de Matos Coutinho, importante mercador que se fixara no Rio de Janeiro, onde adquirira um engenho de açúcar, transferindo-se depois para a capitania do Espírito Santo, acabando por ser detido pelo Santo Ofício, anos mais tarde, em Vitória ${ }^{13}$.

Em Novembro de 1651 falecia Bento de Matos Coutinho. Entre as diversas funções que exerceu, teria ocupado até ao fim da vida o cargo de auditor militar. Realmente, em Dezembro de 1651, o diligente colaborador de Diogo Fernandes Branco, António Gonçalves Pades - que permanecera na Madeira dirigindo as operações comerciais - informava o mercador, numa carta enviada para Lisboa, de que o novo Capitão-General, Bartolomeu de Vasconcelos da Cunha, "por falesimento do Matos", logo nomeara António Ferreira Pinheiro, que desempenhava as funções de ouvidor na Capitania do Funchal, "auditor da guerra"14.

Sabemos ainda que residiu com a mulher e o irmão Lourenço de Matos nuns amplos "aposentos" situados "defronte do Colegio", em cuja igreja haviam, em conjunto, mandado construir a capela de S. Francisco Xavier, onde foram, todos três, sepultados ${ }^{15}$. Conjuntamente com o irmão, era também proprietário de outra quinta, "a que chamão a Cruz", localizada na freguesia de Santo António, "por sima da igreja", constituída por uma vasta fazenda, casa de sobrado "alto e baixo" e lagar"16. Foi mordomo destacado na confraria de Nossa Senhora do Amparo, erecta na Sé do Funchal ${ }^{17}$.

Dos diversos descendentes de Bento de Matos Coutinho, merece especial destaque o já mencionado

$\overline{13}$ Cf. ARM, FOV, cx. 40, no 67, ff. 146 e 219.

Também num manuscrito intitulado Nobiliário de Segredos Genealógicos (Ms. 479 da Biblioteca Pública Municipal do Porto), o anotador Henrique Henriques de Noronha, ao referir-se ao Licenciado Bento de Matos, escreveu que «não há muitos anos saiu sambenitado aqui em Lisboa um parente seu, que havia estado em sua casa, vindo do Brasil». Tratava-se de Luís de Matos Coutinho penitenciado em Lisboa, no auto-de-fé de 10 de Maio de 1682.

Segundo José Gonçalves Salvador (in Os Cristãos-Novos e o Comércio no Atlântico Meridional, cit., p. 219), Mateus da Gama, cunhado de Luís de Matos Coutinho, que se achava na Capitania do Espírito Santo, era seu correspondente na Madeira. Acrescenta que era «seu ex-sócio em viagem que fez a Angola por conveniências de ambos».

14 Vide carta datada de 12 de Dezembro de 1651 (VIEIRA, Alberto - O Público e o Privado na História da Madeira, vol. I, Funchal, Centro de Estudos de História do Atlântico, 1996, p. 233).

15 Através da derradeira disposição do seu irmão Lourenço - que faleceu sem descendência em 1654 -, é possível verificar que o testador mandou-se enterrar «na nossa capella de Sam Francisco Chaviel cita no Colegio da Companhia de Jesus desta cidade que eu e o meo irmão o licenciado Bento de Matos Coutinho e minha cunhada D. Filipa de Vasconcelos sua molher fizemos» (ARM, Tombo do Juízo dos Resíduos e Capelas, Cx. 7, Maço 9). 16 Ibidem.

17 Nesta irmandade, através dos auspícios dos Matos, encontramos vários cristãos-novos, como sejam o licenciado António Lopes da Fonseca, a par de outras figuras proeminentes, tais como Manuel Dias de Andrade, Provedor da Fazenda, D. Tomás Velasquez Sarmiento, governador do presídio, e o almoxarife Diogo Lopes de Andrade (ARM, Confrarias, $\mathrm{n}$ - 71, Termos de entradas de irmãos da confraria de Nossa Senhora do Amparo, 1633-1651, ff. 26v, 28, 30v, 31 e 33).
Lourenço de Matos Coutinho, pai do nosso poeta ${ }^{18}$. Sabemos que estudou, igualmente, na Universidade de Coimbra, havendo registo de matrícula em "Instituta" com certidão passada no $1^{\circ}$ de Maio de $1652^{19}$, e comprovativos da frequência do curso de Cânones, sendo o último registo de 17 de Dezembro de $1653^{20}$. Casou com D. Mariana de Vasconcelos na igreja de S. Pedro, a 13 de Julho de $1660^{21}$. Deste casamento nasceram três filhos ${ }^{22}$, de entre os quais Francisco de Vasconcelos Coutinho ${ }^{23}$, o poeta de Feudo do Parnaso.

Seguindo a tradição familiar, Vasconcelos matriculou-se, aos vinte e um anos, na Universidade de Coimbra $(10 / 12 / 1686)$ com certidão de latim ${ }^{24} \mathrm{e}$, no ano seguinte, a 1 de Outubro, inscreveu-se em direito civil e canónico ${ }^{25}$. Forma-se bacharel em $1696^{26}$, com 31 anos. Pode ainda ser encontrado, no "Livro das Informações Gerais da Universidade", de 1686-87 a 1712-13, no ano lectivo de 95-96, o nome de "Francisco de Vasconcelos Coutinho da Ilha da Madeira", com a seguinte anotação à margem: estudante "suficiente" 27 . Durante a época em que esteve em Coimbra, casou com D. Francisca Antónia Jacinta de Sousa, de quem não teve geração. Em 1697 é nomeado ouvidor da Capitania do Funchal (Nascimento, 1931, p.60).

Salientados os principais aspectos referentes à biografia de Vasconcelos, não poderíamos deixar de tecer algumas considerações sobre a sua produção poética.

Da sua obra destaca-se, em 1718, um elogio dramático para ser representado pelas freiras de Santa Clara, na despedida do governador João de Saldanha da Gama. Inclui também a "Fénix Renascida" (tt. II, III, V) alguns sonetos e a "Fábula de Polifemo e Galateia", autêntica

18 Foi herdeiro de João Afonso de Magalhães, como atesta o valioso fundo arquivístico incorporado no Arquivo Regional da Madeira, intitulado Rol dos Judeus e seus descendentes (ARM, FOV, Cx. 40, no 68, fl. 52).

${ }^{19}$ Cf. Livro de Matrículas 1646-1652, vol. X, fl. 49v.

${ }^{20}$ Cf. Livro de Matrículas 1653-1657, vol. II (Cânones), fl. 20.

21 Vide ARM, Registos de Casamento, Paróquia de S. Pedro, ano de 1660, livro 94, folha 37.

22 Referimo-nos a Bartolomeu de Vasconcelos Coutinho, primogénito; Filipa de Vasconcelos (sem geração) e o poeta Francisco de Vasconcelos. De Bartolomeu, sabemos pelo Registo Paroquial da Madeira - Registo de Baptismo, S. Martinho, livro 240, fl. 169, que foi baptizado a 2 de Dezembro de 1656. Casou com D. Inácia de Noronha da Câmara (Registo Paroquial da Madeira - Registo de Casamento, Sé, livro 55, folha 94) a 28 de Junho de 1689, de quem teve Lourenço Manuel da Câmara e Vasconcelos, editor das obras póstumas (Feudo do Parnaso e Hecatombe Métrico) de seu tio.

23 A propósito da linhagem Coutinho, João Rodrigues de Sá escreveu os seguintes versos (ZUQUETE, Afonso Eduardo Martins (dir) ARMORIAL LUSITANO, cit., p. 184): As cinco estrelas sanguinhas/ em campo douro pintado/ do sangue antigo, \& honrado/ são nobres armas coutinhas, / feitas dum céu estrelado// E sabe-se desta gente/ que ganhou antigamentel segundo a memoria alcançal a casa por sua lança/ que agora tem no presente. Também o Bispo de Malaca, D. João Ribeiro Gaio lhes dedicou a seguinte quintilha: Dos coutos foram senhores/ que tomaram à alarve gentel os Coutinhos que ao presentel em Portugal são maiores, / e godos antigamente.

${ }^{24}$ Cf. Livro de Matrículas, Vol. XXII, cad. 1ํㅡ, fl. 188 (vide fig. 3).

25 Livro de Matrículas 1686-1688, vol. XXII, fl. 67v.

26 Actos e Graus 1695-1698 (22/05/1696), vol. ILIX, fl. 35v.

27 In Arquivo da Universidade de Coimbra. 
paródia da obra homónima de Góngora. O volume II do "Postilhão de Apolo" contém igualmente um poema em tercetos, com o título "À vaidade do mundo".

Não tendo publicado em vida nenhum dos muitos textos que lhe andam atribuídos, sabe-se, no entanto, que postumamente foram publicados "Feudo do Parnaso" (Coutinho, 1729) - composição constituída por 324 tercetos hendecassílabos, que trata da exaltação do rei D. João V, quer através da sua linhagem, quer através dos acontecimentos mais notáveis do seu reinado até à data do poema, não esquecendo a relação do Rei com as Musas, numa clara alusão ao patrocínio das Artes por parte de D. João V -, e "Hecatombe Métrico" (Coutinho, 1729) "consagrado às aras da Cruz Sacratíssima e à pureza imaculada da sempre Virgem Maria", como se lê no frontispício. Trata-se de uma obra constituída por 100 sonetos, que narra a história da redenção do homem desde o pecado de Adão até à paixão redentora de Cristo. Aqui domina a ideia de morte e da efemeridade dos valores terrenos, servida pela riqueza conceptual típica do período Barroco. Ambas as obras foram posteriormente reeditadas e acrescentadas por Lourenço Manuel da Câmara e Vasconcelos, sobrinho do autor, em 1773.

Filho de uma época de profundas metamorfoses, Francisco de Vasconcelos é o exemplo da criatividade portuguesa do período barroco.

Escrevendo ora em português, ora em castelhano, as suas composições deixam não só antever pelos títulos e pelas legendas a marca do cultismo ("Pedindole tabaco"; "A hum loureyro que nasceo nas ruinas de huma Torre"), como também factos históricos presenciados na Madeira ("Residência/ do Governador, / e Capitão General/ da Ilha da Madeira/ João de Saldanha da Gama, / representada pelas freiras de Santa Clara/ na sua despedida") e a reminiscência de um tempo vivido em Coimbra, em que fala com o Mondego estando saudoso:

\section{Soneto}

Falando com o Mondego estando saudoso

Como é, Mondego, igual ao nascimento O meu choro ao que a ti te desempenha; Pois se o teu pranto nasce duma penha, De um penhasco se causa o meu lamento.

Tu do mal, que padeço, estás isento, Porque abrandas chorado a tosca brenha, Mas Filis mais que serra me desdenha, Quando as tuas correntes acrescento.

Se pois a serra dura tanto zela

O teu chorar, que o áspero desterra, E o meu pranto endurece a Fillis bela;

Por teres mais alivio, ou menos guerra Chora tu, pois na serra tens estrela, Eu não, que sem estrela amo uma serra.

(SILVA, 1718, p. 228)
Temas caros ao barroco, como a fragilidade da vida humana, comparecem igualmente na obra do poeta madeirense. Lembremos o poema "Esse baixel nas praias derrotado", talvez o mais conhecido por figurar em diversas antologias:
Soneto
À Fragilidade da vida humana
Esse baixel nas praias derrotado
Foi nas ondas Narciso presumido;
Esse farol nos céus escurecido
Foi do monte libré, gala do prado.
Esse nácar em cinzas desatado
Foi vistoso pavão de Abril florido;
Esse estio em vesúvios encendido
Foi Zéfiro suave em doce agrado.
Se a nau, o sol, a rosa, a primavera
Estrago, eclipse, cinza, ardor cruel
Sentem nos auges de um alento vago,
Olha, cego imortal, e considera
Que és rosa, primavera, sol, baixel,
Para ser cinza, eclipse, incêndio, estrago.

(SILVA, 1718, p. 246)

Trata-se de um dos exemplos mais perfeitos da reinvenção barroca, quer pelo seu virtuosismo verbal, pela sua construção simbólica, uma vez que "a nau, o sol, a rosa, a Primavera" correspondem aos quatro elementos "a água, o fogo, a terra, o ar"; quer pelo espírito da ContraReforma aqui bem patente.

Votado a um imerecido esquecimento, não será mais do que legítimo 'resgatá-lo' das entranhas da memória? Quem poderá ficar indiferente ao poema "Esse jasmim que arminhos desacata", inspirado pela efemeridade intemporal dos valores terrenos?
Soneto
Esse jasmim que arminhos desacata,
Essa aurora que nácares aviva,
Essa fonte que aljôfares deriva,
Essa rosa que púrpuras desata,
Troca em cinza voraz lustrosa prata, Brota em pranto cruel púrpura viva, Profana em turvo pez prata nativa, Muda em luto infeliz tersa escarlata.
Jasmim na alvura foi, na luz aurora, Fonte na graça, rosa no atributo, Essa heróica deidade que em luz repousa.
Porém fora melhor que assim não fora Pois a ser cinza, pranto, barro e luto, Nasceu jasmim, aurora, fonte, rosa.

(SILVA, 1718, p. 232)

Veja-se a forma como organiza a construção das quadras (cada verso da $1^{\text {a }}$ quadra entra em relação 
directa com o verso correspondente da $2^{-}$quadra); a bimembração de todos os versos das quadras que se prolonga ainda pelos tercetos; a junção no último verso de elementos anteriormente disseminados ao longo do poema, mantendo sempre a mesma ordenação. Aqui a realidade da morte, traduzida pela acção da metáfora e da comparação hiperbólica, adquire novos contornos, também eles desenhados metaforicamente - a noção efémera da beleza, talhada pelo destino da morte.

Francisco de Vasconcelos é, então, a encarnação de uma sensibilidade riquíssima sem perder ou desfigurar os traços característicos do Barroco.

Reabilitá-lo é, pois, estabelecer uma ponte entre os requintes do virtuosismo verbal e a multiplicidade de impressões internas e externas de um mundo todo ele composto de reentrâncias.

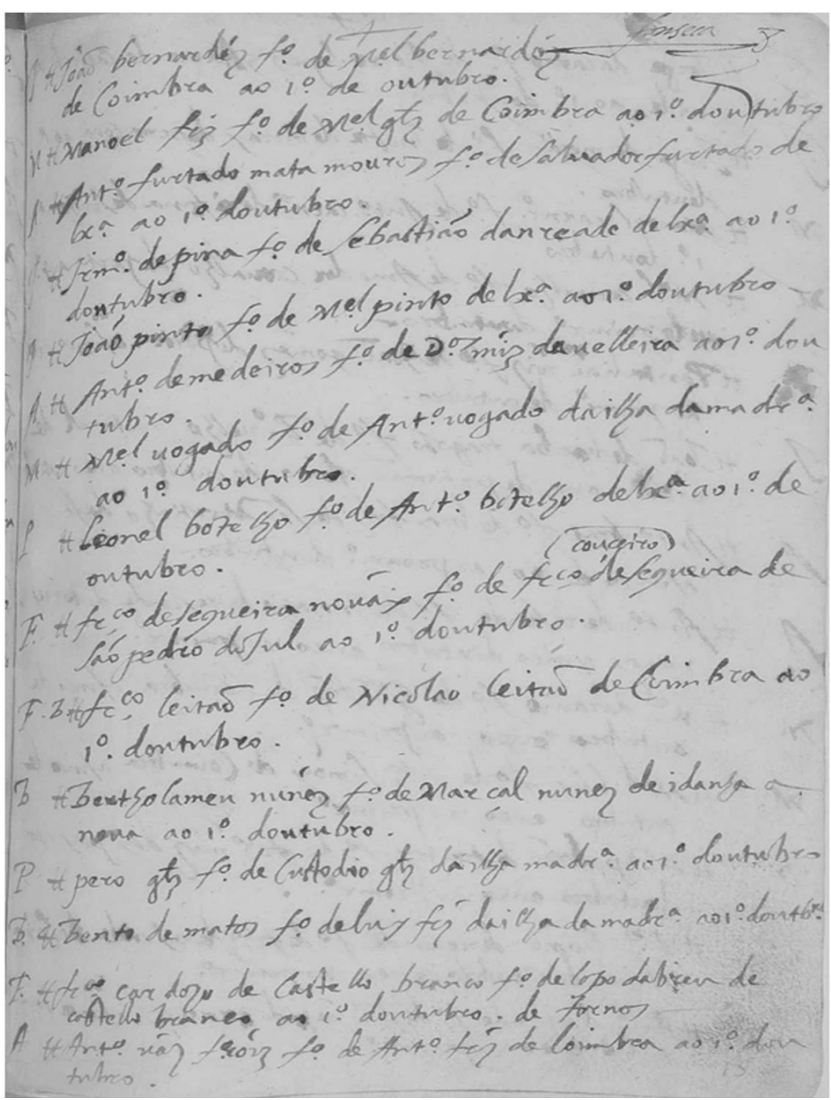

Fig. 1. Primeiro registo de matrícula de Bento de Matos (1/10/1607)

(FI. 8 do, vol. III, do Livro de Matrículas 1600-1612 do Arquivo da Univ. de Coimbra)

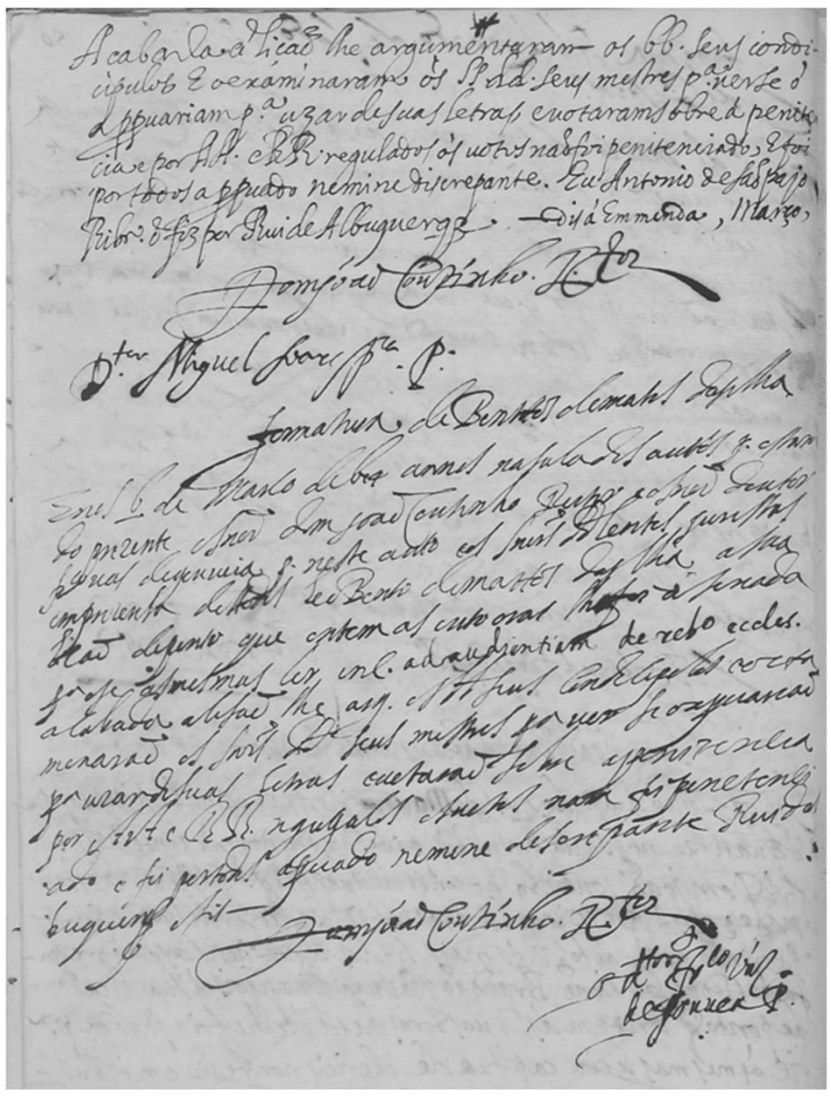

Fig. 2. Formatura de Bento de Matos a 6 de Março de 1614

(FI. 50v, vol. XXIV do Livro de Actos e Graus 1613-1616 do Arquivo da Univ. de Coimbra)

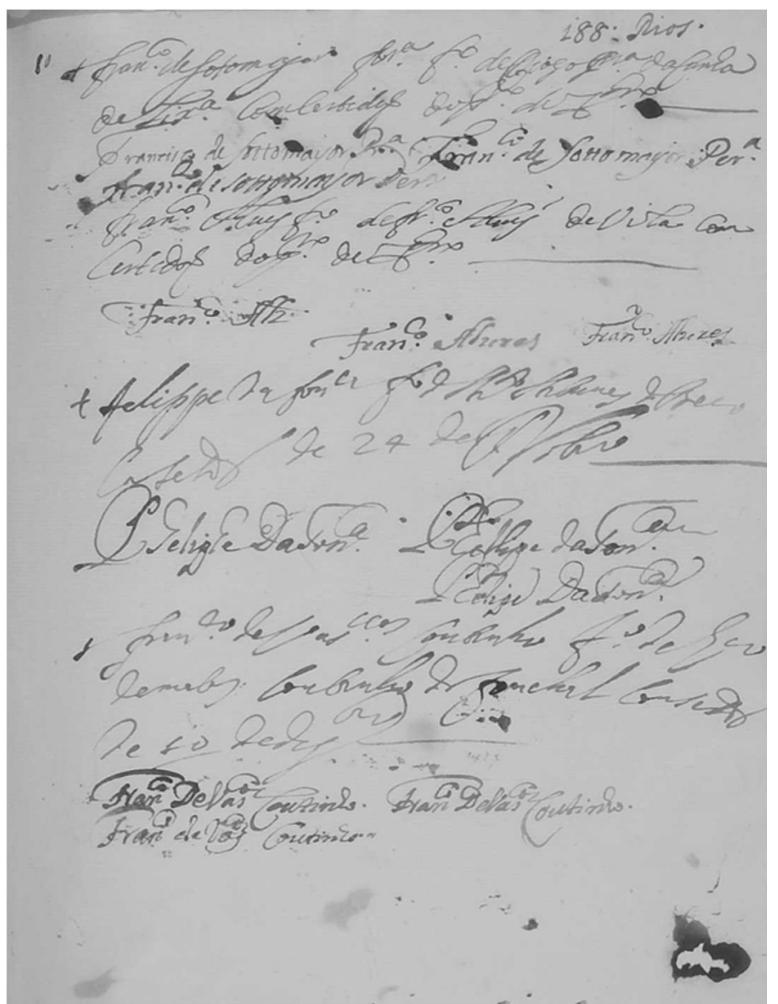




\section{Referências}

\section{A - Fontes manuscritas}

\section{ARQUIVO REGIONAL DA MADEIRA}

1. Livro $5^{\circ}$ dos Baptizados de S. Pedro.

2. Registos de Casamentos-Paróquia de S. Pedro, livro 94.

\section{ARQUIVO DA UNIVERSIDADE DE COIMBRA}

1. Actos e Graus 1610-1613, vol. XXII.

2. Actos e Graus 1613-1616, vol. XXIV.

3. Livro das Informações Gerais da Universidade, 1686-87 a 1712-13.

4. Livro de Matriculas 1600-1612, vol. III.

5. Livro de Matrículas 1646-1652, vol. X.

6. Livro de Matrículas 1653-1657, vol. II.

7. Livro de Matrículas 1686-1688, vol. XXII.

\section{B - Textos poéticos}

MORAIS, José Ângelo de (1761). Eccos, que o Clarim da Fama dá: Postilhão de Apollo. Montado no Pegazo, girando o Universo, para divulgar ao Orbe literario as peregrinas flores da Poezia Portugueza, com que vistosamente se esmaltão os jardins das Muzas do Parnazo.
Academia Universal. Em a qual se recolhem os crystaes mais puros, que os famigerados Engenhos Lusitanos beberão nas fontes de Hipocrene, Helicona e Aganipe. Ecco I. Dedicado ao nosso Fidelissimo Monarcha D. Joseph I. Lisboa: Officina de Francisco Borges de Souza.

SILVA, Matias Pereira da (1716-1728). A Fenis Renascida, ou Obras poeticas dos melhores engenhos portuguezes. Dedicadas ao Excellentissimo Senhor D. Francisco de Portugal, Marquez de Valença, Conde de Vimioso, etc... Lisboa Occidental: Officina de Joseph Lopes Ferreyra Impressor da Serenissima Rainha Nossa Senhora, V tomos.

\section{C - Textos publicados postumamente}

COUTINHO, Francisco de Vasconcelos (1729). Feudo do Parnaso. Lisboa: Pedro Ferreira.

COUTINHO, Francisco de Vasconcelos (1729). Hecatombe Métrico. Lisboa: Pedro Ferreira.

\section{D - Estudos sobre o autor}

NASCIMENTO, João Cabral do (1931). Um poeta madeirense na Fénis Renascida. Francisco de Vasconcelos Coutinho. In: Arquivo Histórico da Madeira, Funchal, vol. I, fasc. 2, pp. 52-62

Recebido: 09 de novembro de 2013 Aprovado: 12 de dezembro de 2013 Contato: cidaliadinis@sapo.pt 